\title{
USO DA GIBERELINA GA 3 NA SELEÇÃO DO PORTE DE BANANEIRA DAS CULTIVARES PRATA E PRATA-ANÃ ${ }^{1}$
}

\author{
JOANA ANGÉLICA BONFIM SILVA DE CARVALHO ${ }^{2}$, CLÓVIS PEREIRA PEIXOTO³, SEBASTIÃO DE OLIVEIRA E \\ SILVA $^{4}$, CARLOS ALBERTO DA SILVA LEDO³, MARIA DE FÁTIMA DA SILVA PINTO PEIXOTO², JULIANA DA SILVA \\ ALVES $^{4}$
}

RESUMO - Este trabalho teve como objetivo desenvolver metodologia de seleção do porte em bananeira mediante o emprego de giberelina. Foi desenvolvido em condições controladas de casa de vegetação da Embrapa Mandioca e Fruticultura Tropical, localizada em Cruz das Almas - BA (12 ${ }^{\circ}$ 48' 38" de latitude sul e 39 $06^{\prime} 26^{\prime \prime}$ de longitude oeste de Greenwich), no período de setembro de 2002 a janeiro de 2003. Para a comparação de diferentes portes de plantas das cultivares Prata-Anã e Prata-Gigante, foram testadas diferentes doses de ácido giberélico $(0 ; 3,0 ; 14,0 ; 29,0 ; 59,0$ e $\left.145 \mu \mathrm{mol} \mathrm{L}{ }^{-1}\right)$, avaliando-se aos 30 e 60 dias após o plantio, altura da planta e altura da primeira folha. Avaliaram-se também o diâmetro do caule, massas fresca e seca da parte aérea e da raiz, e altura da segunda folha, aos 60 dias após o plantio. A concentração que provocou o maior efeito nos caracteres considerados foi de $84 \mu \mathrm{mol} \mathrm{L} \mathrm{L}^{-1}$, sendo que, na variável altura da planta, aos 60 dias foi a de $90,26 \mu$ mol $\mathrm{L}^{-1}$. Para todas as variáveis estudadas, observou-se um ponto de máximo em torno da dose de $90 \mu \mathrm{mol} \mathrm{L}{ }^{-1}$ de giberelina. A concentração de $94,13 \mu \mathrm{mol} \mathrm{L}^{-1}$ de ácido giberélico $\left(\mathrm{GA}_{3}\right)$ foi a mais eficiente na identificação precoce do porte de genótipos de Prata-Anã e Prata-Gigante. O momento adequado para efetuar a separação dos genótipos de diferentes portes é aos 60 dias após o plantio, e a variável que deve ser observada no instante da seleção, é a altura da segunda folha.

Palavras-chave: melhoramento, ácido giberélico, mutação, altura de planta, musa spp.

\section{USE OF GIBBERELLIN GA IN THE SELECTION OF BANANA HEIGHT OF PRATA AND DWARF PRATA CULTIVARS}

\begin{abstract}
This work aimed to develop a methodology for the selection of plants with different heights using gibberellin. The study was carried out under greenhouse conditions at Embrapa Cassava and Tropical Fruits, located at Cruz das Almas -BA (12 48'38" South latitude and 39 06'26" longitude West), during the period of September 2002 through January 2003. For the comparison of different heights of Prata Dwarf and Prata Gigante cultivars, different concentrations of gibberellic acid $\left(0 ; 3.0 ; 14.0 ; 29.0 ; 59.0\right.$; and $\left.145.0 \mu \mathrm{mol} \mathrm{L}^{-1}\right)$ were used in order to evaluate plant height and height of first leaf at 30 and 60 days after planting. Also the stem diameter, fresh and dry matter of the root and above ground plant parts and height of the second leaves, were evaluated at 60 days after planting. The concentration that demonstrated the greatest effect in the characteristics evaluated was $84 \mu \mathrm{mol} \mathrm{L}^{-1}$; whereas for plant height at 60 days was $90.26 \mu \mathrm{mol} \mathrm{L}-1$. In general, a maximum peak around $90 \mu \mathrm{mol} \mathrm{L} \mathrm{L}^{-1}$ of gibberellin dosage was observed for the variables in study. The concentration of $94.13 \mu \mathrm{mol} \mathrm{L}^{-1}$ of gibberellic acid (GA) was the most efficient in the early identification of height of the Prata Dwarf and Prata Gigante. The adequate time to separate the genotypes with different heights is at 60 days after planting and the variable that must be observed at the time of the selection is the height of the second leaf.
\end{abstract}

Index terms: improvement, gibberellic acid, mutation, plant of height, $m u s a$ spp.

\section{INTRODUÇÃO}

A cultura da bananeira assume importância econômica e social em todo o mundo, sendo cultivada em mais de 80 países tropicais, principalmente por pequenos agricultores. O Brasil é o terceiro produtor mundial de banana (segunda fruta mais consumida no País), com uma produção aproximada de 6,5 milhões de toneladas, em área cultivada de 485 mil hectares (FAO, 2004). As cultivares mais difundidas (Prata-Anã, Pacovan, Maçã, e Terra) pertencem ao grupo $\mathrm{AAB}$ e são suscetíveis à Sigatoka-negra. As variedades Pacovan e Terra apresentam porte elevado, dificultando seu cultivo (Silva et al., 2002).

A mutagênese in vitro é uma técnica de biotecnologia usada para corrigir defeitos de um ou poucos genes, em genótipos de grande interesse (porte alto), sendo considerada como um ajuste fino para a finalização de uma variedade (Perez Ponce \& Orellana, 1998). O uso da mutação para redução de porte poderá ser facilitado caso haja um sistema precoce e eficiente de identificação de mutantes. Assim, o emprego de giberelinas constitui-se em uma alternativa para trabalhos desta natureza (Damasco et al., 1996).

A aplicação exógena do ácido giberélico sobre variantes somaclonais para altura de plantas em bananeiras mostrou que o fitorregulador, ao ser aplicado, provoca crescimento acelerado. Da mesma forma, um decréscimo significante na produção foliar e de raiz foi observado em todas as plantas tratadas com GA (Sandoval, 1999)
A produção de cultivares melhoradas por qualquer método é um processo baseado nos princípios de geração e aproveitamento de variabilidade genética, seleção de genótipos úteis e testes comparativos para demonstrar a superioridade dos genótipos selecionados para características agronômicas específicas. Usando os métodos tradicionais, estes estádios são extremamente laboriosos e demorados. Por outro lado, o uso da biotecnologia fornece várias alternativas para a rápida ampliação da variabilidade genética (Roux et al., 1994; Perea \& Constabel, 1996).

O trabalho teve como objetivo avaliar o efeito do ácido giberélico no crescimento de genótipos de bananeira, visando a desenvolver uma metodologia de seleção de plantas quanto ao porte.

\section{MATERIALE MÉTODOS}

O experimento foi conduzido na Embrapa Mandioca e Fruticultura Tropical, em condições controladas de casa de vegetação, em Cruz das Almas - BA (12 ${ }^{\circ} 48^{\prime} 38^{\prime \prime}$ de latitude sul e $39^{\circ} 06^{\prime} 26^{\prime \prime}$ de longitude oeste de Greenwich), no período de setembro de 2002 a janeiro de 2003. Foram usadas gemas de $10 \mathrm{~cm}$ a $12 \mathrm{~cm}$ das cultivares triplóides (AAB) Prata-Anã de porte médio a alto e Prata-Gigante de porte alto, provenientes do banco de matrizes do Campo (Biotecnologia), em Paracatu-MG.

O cultivo do material na fase de crescimento foi feito em meio

\footnotetext{
${ }^{1}$ (Trabalho 093/2005). Recebido: 03/06/2005. Aceito para publicação: 08/12/2005.

${ }^{2}$ Engenheira Agrônoma. Mestre em Ciências Agrárias/UFBA - joana@bol.com.br

${ }^{3}$ Eng $^{\circ}$ Agrônomo. DSc. Escola de Agronomia da UFBA - cpeixot@ufba.br;fpeixoto@ufba.br

${ }^{4}$ Eng ${ }^{\circ}$ Agronomo. DSc. Embrapa Mandioca e Fruticultura. Cruz das Almas. BA. ssilva@cnpmf.embrapa.br, ledo@cnpmf.embrapa.br

${ }^{4}$ Graduanda em Agronomia, Escola de Agonomia, Universidade Federal da Bahia, Cruz das Almas-BA - jualvesagr@yahoo.com.br.
} 
de cultura básico MS suplementado com $30 \mathrm{~g} \mathrm{~L}^{-1}$ de sacarose e benzilaminopurina (BAP), na concentração de $3,0 \mathrm{mg} \mathrm{L}^{-1}$, e solidificado com $2,2 \mathrm{~g} \mathrm{~L}^{-1}$ de Phytagel. Na fase de enraizamento, utilizou-se de MS, $0,25 \mathrm{mg} \mathrm{L}^{-1} \mathrm{de}$ ácido naftaleno acético (ANA) e ágar $8 \mathrm{~g} \mathrm{~L}^{-1}$ como geleificante. $\mathrm{O} \mathrm{pH}$ do meio foi ajustado em 5,8 e autoclavagem foi realizada a $120^{\circ} \mathrm{C}$, por 20 minutos. Os explantes foram então colocados em frascos de $3,5 \mathrm{~cm} \times 8 \mathrm{~cm}$ (altura), contendo $15 \mathrm{~mL}$ de meio de cultura, sendo então conduzidos à sala de cultura com fotoperíodo de 16 horas de luz, intensidade luminosa de $50 \mathrm{mmol} \mathrm{m}^{2} \mathrm{~L}^{-1}$ e temperatura de $26 \pm 2^{\circ} \mathrm{C}$.

Em intervalos de 35 e 40 dias, as culturas foram repicadas, sendo feitos cinco subcultivos. Posteriormente, as plântulas foram transplantadas para tubetes, contendo substrato Plantmax (composto por casca de madeira processada, vermiculita expandida, carvão granulado e turfa processada e enriquecida com macro e micronutrientes) e aclimatadas em telado com sombrite $50 \%$, com controle de luminosidade e de irrigação feita por nebulização automática.

$\mathrm{O}$ ácido giberélico $\left(\mathrm{GA}_{3}\right)$ foi aplicado 10 dias após o plantio, nas primeiras horas da manhã, com pulverizador manual de $500 \mathrm{~mL}$, planta por planta, evitando atingir os demais tratamentos. Foram aplicadas as seguintes concentrações de $\mathrm{GA}_{3}: 0 ; 3,0 ; 14,0 ; 29,0 ; 59,0 \mathrm{e}$ $145,0 \mu \mathrm{mol} . \mathrm{L}^{-1}$. Para uniformizar o manuseio, a testemunha foi pulverizada com água destilada. A pulverização foi feita nas primeiras horas da manhã. As plantas foram irrigadas no dia anterior, voltando a serem irrigadas normalmente, 24 horas depois da aplicação do fitorregulador.

Trinta dias após a aplicação do $\mathrm{GA}_{3}$, foram avaliadas a altura da planta e da primeira folha (bainha mais pecíolo). Um mês depois da primeira avaliação, foram avaliados os seguintes caracteres: altura da planta, altura da primeira e segunda folhas (bainha mais pecíolo) e teores de matéria fresca e seca da raiz e da parte aérea.

$\mathrm{O}$ delineamento experimental foi o inteiramente casualizado, em esquema fatorial $6 \times 2$, seis concentrações de $\operatorname{GA}_{3}(0 ; 3,0 ; 14,0 ; 29,0$; 59,0 e $145,0 \mu \mathrm{mol} . \mathrm{L}^{-1}$ ) e duas cultivares triplóides de bananeira (Prata-
Anã e Prata-Gigante), sendo utilizadas 30 repetições para as avaliações feitas aos 30 dias e 12 repetições para as avaliações feitas aos 60 dias, após a aplicação do fitorregulador. Realizou-se análise de regressão para o fator concentração da giberelina, sendo aplicado o teste F para o fator cultivar. As análises estatísticas foram realizadas pelo programa estatístico SISVAR - Sistema de Análise de Variância para Dados Balanceados, desenvolvido por Ferreira (2000).

\section{RESULTADOS E DISCUSSÃO}

Na Figura 1A, é apresentado o modelo de regressão quadrática e respectivos coeficientes de determinação, para a variável altura de planta aos 30 dias (AP1) para as cultivares Prata-Anã e Gigante submetidas a diferentes doses de giberelina. Inicialmente, a cultivar Prata-Gigante apresentou plantas mais altas, o que já era esperado. Entretanto, com o aumento das doses, houve uma inversão, e a cultivar Prata-Anã teve plantas de maior porte comparada à Prata-Gigante. Isso pode ter ocorrido, provavelmente, em função de as doses elevadas proporcionarem inibição do crescimento na cultivar Prata-Gigante, atuando de forma inversa a sua função. Estas doses são consideradas elevadas, uma vez que a planta já apresenta giberelina endógena.

Doses elevadas também podem levar na cultivar Prata-Gigante uma redução no diâmetro do pseudocaule e estreitamento da bainha, resultando no desprendimento dessa, além da elongação do pecíolo e lanceolamento da lâmina foliar, que apresenta menos intensidade na cultivar Prata-Anã. As mesmas características foram observadas por Cote et al. (1993) e Sandoval (1999), avaliando características morfológicas em plantas em fase de aclimatação cultivadas in vitro, tratadas com $\mathrm{GA}_{3}$.

Analisando-se as Figuras 1B, 2A, 2B e 2C, com respectivos modelos de regressão quadrática e coeficientes de determinação para as variáveis massa fresca da parte aérea e da raiz, e massa seca da parte

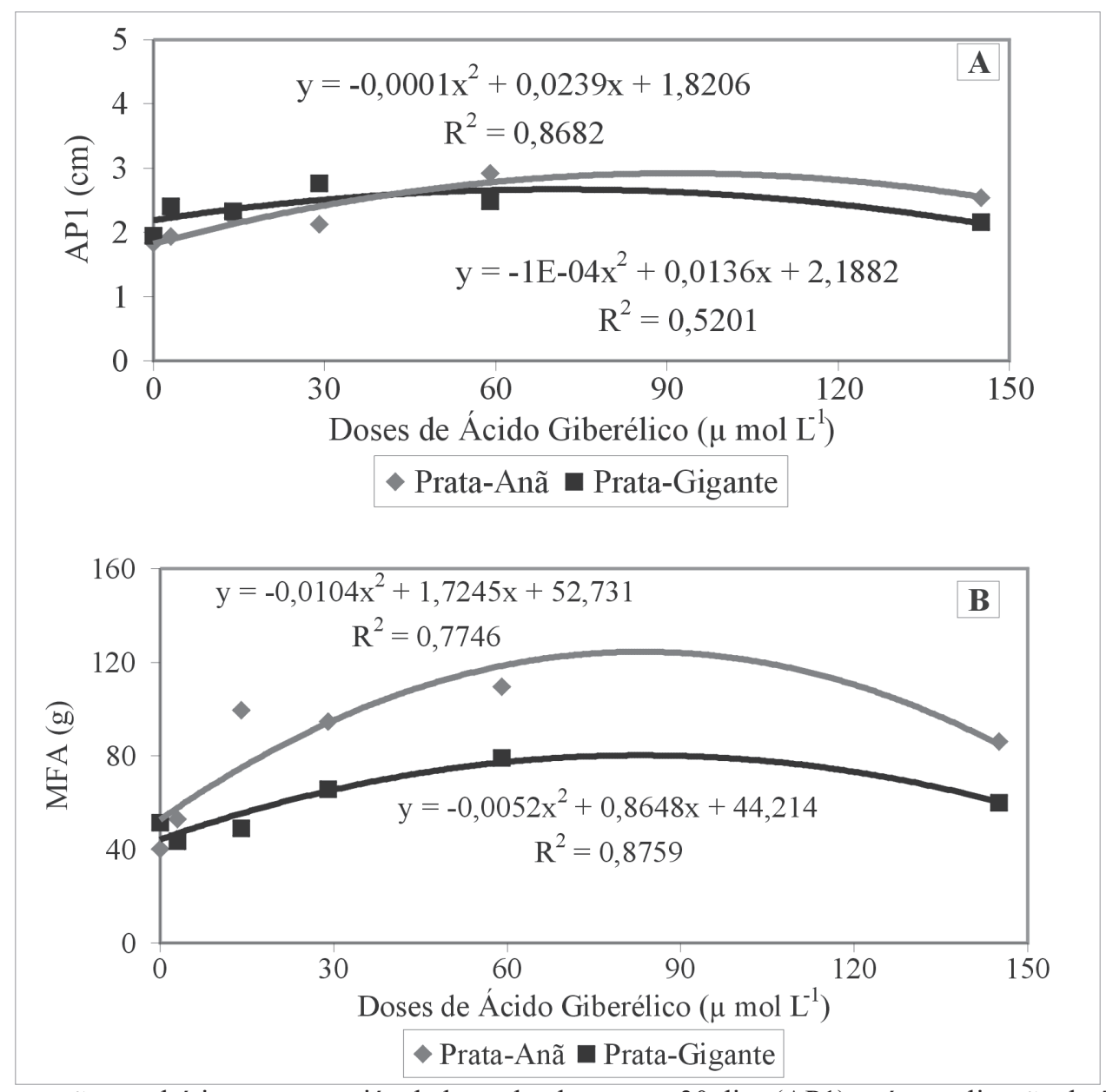

FIGURA 1 - Modelo de regressão quadrática para a variável altura da planta, aos 30 dias (AP1) após a aplicação de ácido giberélico (A) e massa fresca da parte aérea (MFA) (B) em bananeira (Musa spp) sob seis concentrações de ácido giberélico $\left(\mathrm{GA}_{3}\right)$, nas cultivares Prata-Anã e Prata-Gigante. Cruz das Almas-BA, 2003. 


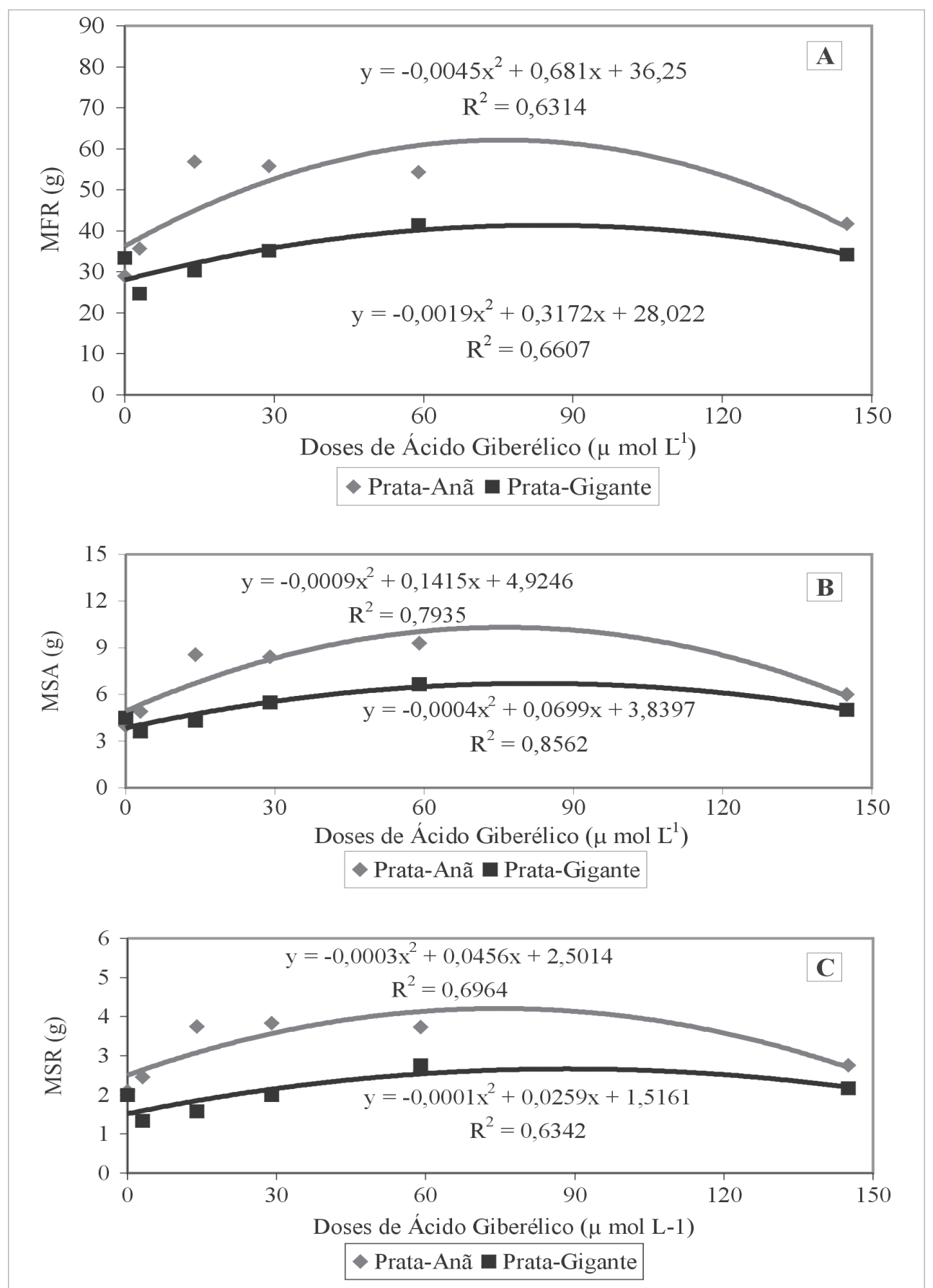

FIGURA 2 - Modelo de regressão quadrática para a variável massa fresca da raiz (MFR) (A), massa seca da parte aérea (MAS) (B) e massa seca da raiz (MSR) (C) de bananeira (Musa spp) sob seis concentrações de ácido giberélico ( $\left.\mathrm{GA}_{3}\right)$, nas cultivares Prata-Anã e Prata-Gigante, 60 dias após o plantio. Cruz das Almas-BA, 2003.

aérea e da raiz, pode-se verificar que a cultivar Prata-Anã mostrou valores mais elevados em relação à cultivar Prata-Gigante em todas as situações. Observa-se também que houve queda acentuada a partir dos valores estimados (Tabela 1), comprovando o que já tinha sido observado na Figura 1A para altura de planta, aos 30 dias (AP1), ou seja, que o ácido giberélico $\left(\mathrm{GA}_{3}\right)$, a partir de $120 \mu \mathrm{mol} \mathrm{L}^{-1}$, apresenta ação inversa, passando de estimulante a inibidor do crescimento.

Na Figura 3, são apresentados o modelo de regressão quadrática e respectivo coeficientes de determinação para a variável altura da primeira folha aos 30 dias (AI1). Verifica-se que ambas as cultivares apresentaram o mesmo comportamento, não sendo observadas diferenças entre elas. Apesar de a altura das cultivares serem diferentes, elas apresentam a mesma constituição genética e provavelmente a mesma reação a giberelina exógena, pressupondo que a Prata-Anã apresenta deficiência na síntese da giberelina endógena, só respondendo a estímulo da aplicação exógena. Por outro lado, a cultivar Prata-Gigante, apesar de possuir giberelina endógena, nesta etapa inicial de aclimatação, só responde à aplicação de giberelina exógena, em função de seu mecanismo de síntese não se apresentar

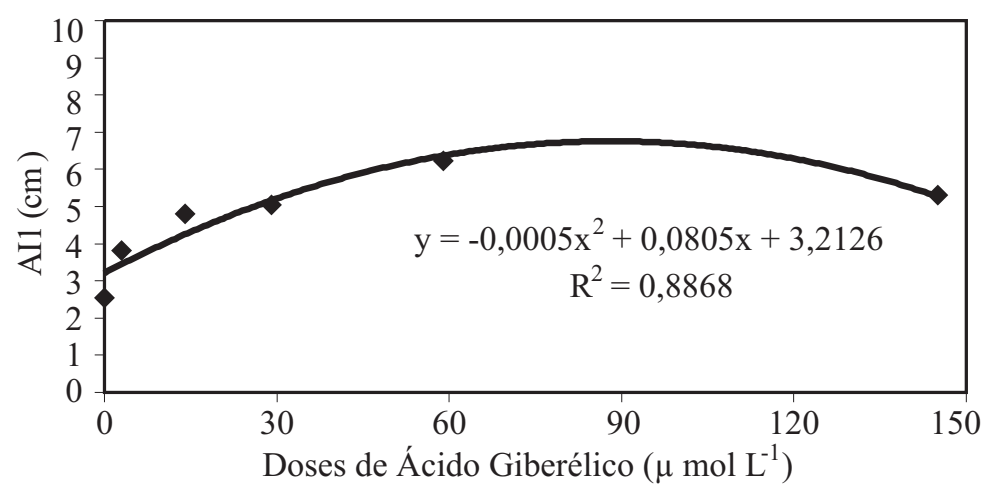

FIGURA 3 - Modelo de regressão quadrática para a variável altura da primeira folha, aos 30 dias após a aplicação de $\mathrm{GA}_{3}(\mathrm{AI} 1)$, em bananeira (Musa spp) sob seis concentracões de ácido giberélico $\left(\mathrm{GA}_{3}\right)$, nas cultivares Prata-Anã e Prata-Gigante. Cruz das Almas-BA, 2003.

perfeitamente organizado, sendo sua superioridade verificada mais tardiamente, quando o seu mecanismo já apresenta condições 
TABELA 1 - Estudo de regressão quadrática da altura de planta aos 30 e 60 dias, massa seca da parte aérea e da raiz aos 60 dias após a aplicação de ácido giberélico $\mathrm{GA}_{3}$ nas cultivares Prata-Anã e Prata-Gigante. Cruz das Almas-BA, 2003.

\begin{tabular}{|c|c|c|}
\hline \multirow[t]{2}{*}{ Caráter } & \multicolumn{2}{|c|}{ Regressões } \\
\hline & Prata-Anã & Prata-Gigante \\
\hline $\begin{array}{l}\text { Altura de Planta } 30 \text { dias após a aplicação } \\
\text { do } \mathrm{GA}_{3}\end{array}$ & $\mathrm{R}^{2}=0,8682$ & $\mathrm{R}^{2}=0,5201$ \\
\hline \multirow{3}{*}{$\begin{array}{l}\text { Altura de Planta } 60 \text { dias após a aplicação } \\
\text { do } \mathrm{GA}_{3}\end{array}$} & $Y=-0,0014 x^{2}+0,234 x+15,95$ & $Y=-0,0009 x^{2}+0,1745 x+14,967$ \\
\hline & $\mathrm{R}^{2}=0,5603$ & $\mathrm{R}^{2}=0,9116$ \\
\hline & P. $\max =83,57$ & Valor máximo estimado $=96,94$ \\
\hline $\begin{array}{l}\text { Altura da } 1^{\mathrm{a}} \text { folha } 30 \text { dias após a } \\
\text { aplicação do } \mathrm{GA}_{3}\end{array}$ & P.max $=87,50$ & Valor máximo estimado $=87,50$ \\
\hline \multirow{4}{*}{$\begin{array}{l}\text { Altura da } 1^{\mathrm{a}} \text { folha } 60 \text { dias após a } \\
\text { aplicação do } \mathrm{GA}_{3}\end{array}$} & $Y=-0,0009 x^{2}+0,1463 x+5,3597$ & $Y=-0,0009 x^{2}+0,1791 x+4,4596$ \\
\hline & $\mathrm{R}^{2}=0,7884$ & $\mathrm{R}^{2}=0,8543$ \\
\hline & P.max $=81,27$ & Valor máximo estimado $=99,50$ \\
\hline & $Y=-0,0008 x^{2}+0,1506 x+8,701$ & $Y=-0,0013 x^{2}+0,2817 x+5,8812$ \\
\hline $\begin{array}{l}\text { Altura da } 2^{\mathrm{a}} \text { folha } 60 \text { dias após a } \\
\text { aplicação do } \mathrm{GA}_{3} \\
\text { Massa seca da raiz } 60 \text { dias }\end{array}$ & $\mathrm{R}^{2}=0,8401$ & $\mathrm{R}^{2}=0,9157$ \\
\hline \multirow{2}{*}{ Massa seca parte área 60 dias } & $\mathrm{R}^{2}=0,7935$ & $\mathrm{R}^{2}=0,8562$ \\
\hline & P. $\max =80,28$ & Valor máximo estimado $=87,38$ \\
\hline
\end{tabular}

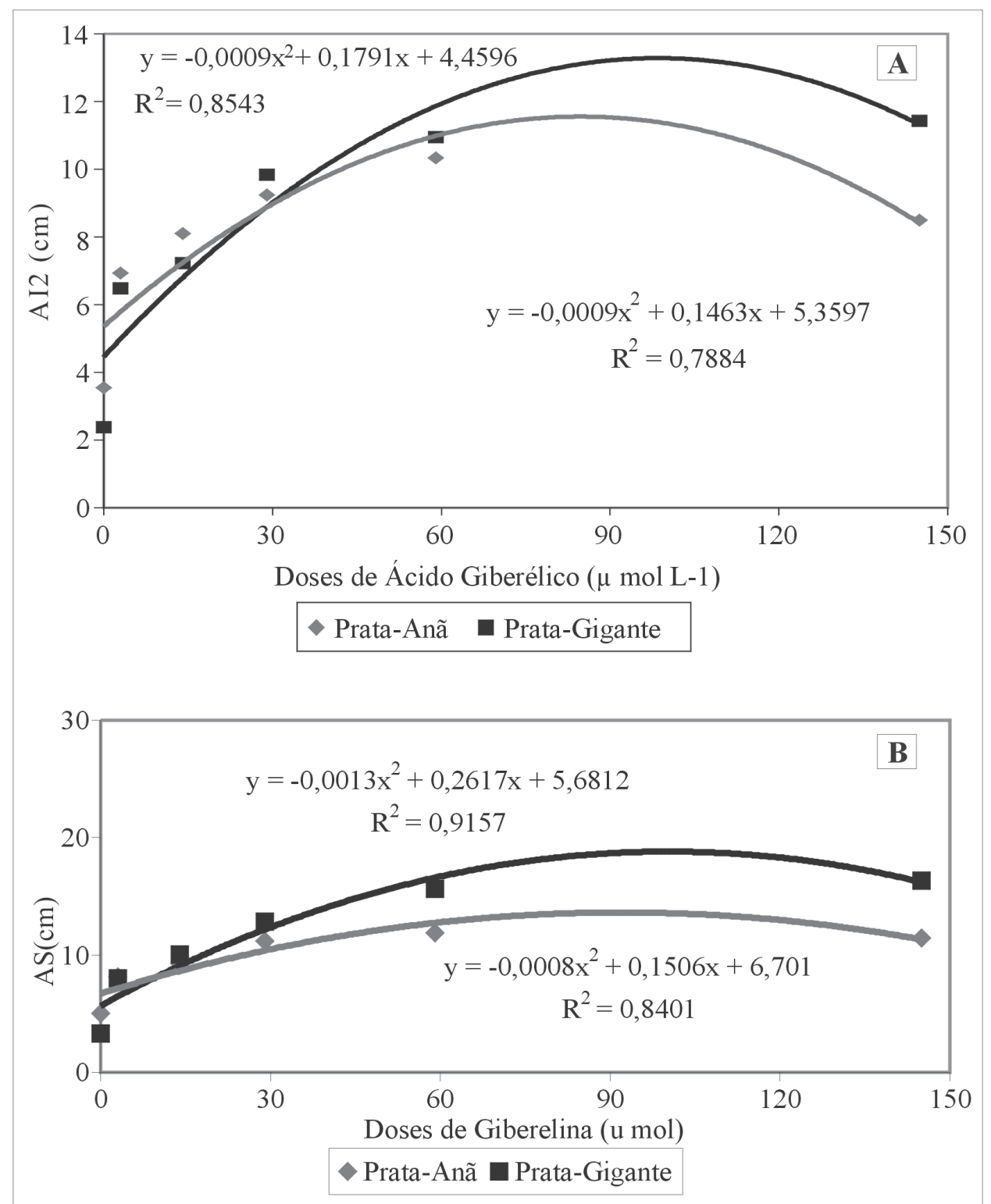

FIGURA 4 - Modelo de regressão quadrática para a variável altura da primeira folha (A12) (A) e altura da segunda folha (AS) (B) aos 60 dias após a aplicação de ácido giberélico $\mathrm{GA}_{3}$, em bananeira (Musa spp) sob seis concentrações, nas cultivares Prata-Anã e Prata-Gigante. Cruz das Almas-BA, 2003. 
fisiológicas de desenvolver adequadamente suas funções. Isto pode ser verificado a partir da dose de $30 \mu \mathrm{mol} \mathrm{L}^{-1}$, onde é observada superioridade da cultivar Prata-Gigante em relação à cultivar Prata-Anã (Figura 4A). Essa superioridade pode ser verificada na altura da segunda folha, em que a cultivar Prata-Gigante é capaz de expressar sua máxima potencialidade (Figura 4B).

$\mathrm{Na}$ Tabela 1, encontram-se os resultados do estudo da regressão da altura de planta aos 30 e 60 dias, após aplicação do $\mathrm{GA}_{3}$, altura da primeira e segunda folhas, teor de massa seca da raiz e da parte aérea aos 60 dias das cultivares Prata-Anã e Prata-Gigante. O coeficiente de determinação $\left(\mathrm{R}^{2}\right)$ variou de 0,5201 para altura de planta, aos 30 dias, a 0,9191, para altura da primeira folha, aos 30 dias, na variedade PrataGigante. Na Prata-Anã, o maior coeficiente de determinação foi de altura da $1^{\text {a }}$ folha, aos 30 dias $(0,9191)$, e o menor o da altura da planta, aos 60 dias $(0,5603)$. Com exceção dos $\mathrm{R}^{2}$ observados na altura de planta, aos 30 dias após a aplicação do $\mathrm{GA}_{3}$, na variedade Prata-Gigante $(0,5201)$ e altura de planta aos 60 dias, na Prata-Anã $(0,5603)$, todos os demais $\mathrm{R}^{2}$ podem ser considerados de médios a altos, mostrando que as equações quadráticas utilizadas explicaram, consideravelmente, as variações observadas nos dados experimentais. A partir de seus respectivos valores máximos estimados $(\mathrm{P}=68,00)$ para a cultivar Prata-Gigante e $(\mathrm{P}=119,50)$ para a cultivar Prata-Anã, inicia-se um processo de redução no crescimento devido a fatores distintos. Na Prata-Anã, pode ser devido à degradação do $\mathrm{GA}_{3}$ no crescimento inicial e a deficiência na síntese desse hormônio. Já na Prata-Gigante, esse decréscimo deve ser em função das altas dosagens de $\mathrm{GA}_{3}$ exógenas incrementadas pela giberelina endógena.

\section{CONCLUSÕES}

1.A concentração estimada de $94,13 \mu \mathrm{mol} \mathrm{L}^{-1}$ de ácido giberélico $\left(\mathrm{GA}_{3}\right)$ é a mais eficiente na identificação precoce do porte de genótipos de Prata-Anã e Prata-Gigante.

2. O momento adequado para efetuar a separação entre os genótipos quanto ao porte é aos 60 dias após a aplicação da giberelina, e a variável que deve ser observada no instante da seleção, é a altura da segunda folha, 60 dias após o plantio.

\section{REFERÊNCIAS}

COTE, F. X.; SANDOVAL , J. A. MARIE. ; ALBOIRON, E. Variations in micropropated and plantains: literature survey. Fruits, Paris,v. 48, p. $15-22,1993$.

DAMASCO, O.P.; GODWIN, I.D.; SMITH, M.K.; ADKINS, S.W. Gibberellic acid detection of dwarf offtypes in micropropagated Cavendish bananas. Australian Journal of Experimental Agriculture, Collingwood, v.3, p.237-241, 1996.

FOOD AND AGRICULTURE ORGANIZATION. Disponível: site FAO (23-02-2005) http://apps.fao.org/page/collections. 2004.

FERREIRA, D. F. Análises estatísticas por meio do Sisvar para Windows versão 4.0. In: REUNIÃO ANUAL DA REGIÃO BRASILEIRA DA SOCIEDADE INTERNACIONAL DE BIOMETRIA, 45., 2000, São Carlos. Programa e resumos... São Carlos: UFSCar, 2000. p.255258.

PEREZ PONCE J; ORELLANA, P. Musa Improvement in Cuba. In: JONES D.R. (Ed.) The improvement and testing of musa: a global workshop. Montpellier: INIBAD, 1998. p.203-206.

PEREA, D. M.; CONSTABEL, C. Estratégias para el mejoramiento de bananos e platanos. Augura- Revista, Bogotá, v.19, n.1, p. 40, 1996.

ROUX, N.;AFZA, R.; BRUNNER, H.; MORBURGO, R.; VAN DUREN, M. Complementary approaches to cross-breeding and Mutation Breeding for Musa Improvement. In: JONES D.R. (Ed.). The improvemnt and testing of Musa: a global workshop. Montpellier: INIBAP, 1994. p. $213-218$.

SANDOVAL, J.A.F. In vitro recognition of high stacture somaclonal variants in banana (Cv. 'Grand Naine, Musa AAA) response to a GA treatment. Guapilles, Costa Rica, v.24, p.11-19, 1999.

SILVA, S. O.; FLORES, J. C. O; LIMANETO, F. P. Avaliação de cultivares e híbridos de bananeira em quatro ciclos de produção. Pesquisa Agropecuária Brasileira, Brasília, v.37, n.11, p.1567-1574, 2002. 